\title{
Nemaline Myopathy 8
}

National Cancer Institute

\section{Source}

National Cancer Institute. Nemaline Myopathy 8. NCI Thesaurus. Code C129871.

An autosomal recessive myopathy caused by mutations in the KLHL40 gene, encoding Kelch-like protein 40 . The phenotype is highly variable, and as such attempts at classification by clinical features is not optimal. Generally, affected individuals have generalized muscle weakness, and typically involves proximal muscles, the face, bulbar and respiratory muscles. 